\title{
Effects of Ruta graveolens total and flavonoids extracts on rat blood glucose, cholesterol, triglycerides and urea comparing synthetic drugs
}

\author{
MITRA NOORI ${ }^{1, \boldsymbol{v}}$, MEHRANA JAFARI ${ }^{1}$, HANIE AZIMI ${ }^{2}$, MEHDI NODE-FARAHANI ${ }^{\mathbf{1}}$ \\ ${ }^{1}$ Department of Biology, Faculty of Science, Arak University. Arak 38156-8-8349-Iran. Tel/Fax. +98-86-34173406, `email: m-noori@araku.ac.ir \\ ${ }^{2}$ Faculty of Pharmacy and Pharmaceutical Sciences Research Center, Tehran University of Medical Sciences (TUMS), Tehran 1417614411, Iran
}

Manuscript received: 11 October 2018. Revision accepted: 9 January 2019.

\begin{abstract}
Noori M, Jafari M, Azimi H, Node-Farahani M. 2019. Effects of Ruta graveolens total and flavonoids extracts on rat blood glucose, cholesterol, triglycerides and urea comparing synthetic drugs. Nusantara Bioscience 11: 23-29. Rue (Ruta graveolens L.: Rutaceae) is a medicinal plant that is used to treat many diseases in America, Asia and Europe due to its pharmaceutical properties. So far more than 120 different phytochemicals such as flavonoids have been extracted and identified from the species, which make it valuable in traditional medicine and manufacturing of synthetic drugs. Due to its endemic and high potential pharmacological effects, this study examined the oral effect of each of its total, flavonoids and non-flavonoids extracts on reducing blood glucose, cholesterol, triglycerides and urea in STZ-diabetic rats comparing to control and Atorvastatin, Allopurinol, Metformin as synthetic drugs. Aerial part of the plant was collected from around Yazd, Iran and dried in shade, crushed and extracted in $70 \%$ ethanol in three steps. Total and flavonoid extracts were prepared after rotary evaporation, then were used for making required doses after calculation. The plant flavonoids were identified using two-dimensional, thin-layer chromatography and TLC Scanner3 methods. Atorvastatin, Allopurinol and Metformin were obtained and also appropriate doses were prepared. Thirty-six adult male Wistar rats were divided in 12 groups $(n=3)$ : control, synthetic drugs control, total and flavonoids control, STZ-diabetic control, diabetic treated with synthetic drugs, total and flavonoids extracts, then weighed. All rats were treated orally at a specific time for 2 weeks. Subsequently, the secondary rat weights were determined and blood donation was performed after anesthesia. Then, blood serum glucose, cholesterol, triglycerides and urea were determined by spectrophotometry using commercial enzymatic chlorometric assay kits. All data were analyzed using EXCEL and SPSS software. Results showed aerial part of $R$. graveolens contains flavones $C$ and $C$-/ $O$ glycosides, flavonoid sulphates and had no aglycones. Apigenin, chrycin, isorhamnetin, kaempferol, myricetin, quercetin, rutin and vitexin were found in the species aerial part. This plant had $329 / 99 \mathrm{gr} / \mathrm{kgDW}$ of effective material and $257.7 \mathrm{~g} / \mathrm{kgDW}$ of flavonoids. The lowest blood glucose levels were observed in treated Metformin and flavonoids control rats respectively. Diabetic rats treated with $R$. graveolens total extract had the lowest blood cholesterol, urea and glucose levels. The highest renal damage was observed in control diabetic rats and the least renal damage was observed in the STZ-diabetic rats treated with the plant total extract. These results indicate that $R$. graveolens extract and its rutin contained antihyperglycemia, antihyperlipidemia, insulinity and protective properties.
\end{abstract}

Keywords: Blood glucose, cholesterol, flavonoids, medicinal plant, Ruta graveolens.

\section{INTRODUCTION}

The prevalence of diabetes for all age-groups worldwide was estimated to be $2.8 \%$ in 2000 and $4.4 \%$ in 2030. The total number of people with diabetes is projected to rise from 171 million in 2000 to 366 million in 2030 (Wild et al. 2004). Diabetes mellitus (DM) is the world's largest growing metabolic disorder of the endocrine system, presently affecting about 5-10 percent people around the globe (Arif et al. 2014). Diabetes is characterized by hyperglycemia together with biochemical alterations of lipid metabolism (Jensen et al. 1988). Also El Agraa et al. (2002) reported correlation between clinical effects and pathological changes in various organs, alterations in serum constituents, hematological values and the concentrations of metal ions in the tissues (El Agraa et al. 2002).

Since ancient times, plants have been an exemplary source of medicine. Various medicinal plants are effective on treating diabetes (Grover et al. 2002; Arumugam et al. 2013). Several clinical trials have documented beneficial modifications of the LDL/HDL ratio after intake of flavonoid-containing food products (Weggemans and Trautwein 2003). Alarcon-Aguilara et al. (1998) examined anti-hyperglycemic effect of 28 medicinal plants for treatment of diabetes mellitus. Each plant was processed in traditional way and intragastrically administered to temporarily hyperglycemic rabbits (Alarcon-Aguilara et al. 1998). Numerous studies reported the clinical benefits of plants from family Rutaceae for diabetes treatment. Citrus paradisi Macfad (Rutaceae) seed methanolic extract is used for treatment of anemia, diabetes mellitus and obesity in human (Adeneye 2008). Murraya koenigii (Rutaceae) leaves are traditionally used to treat diabetes (Dineshkumar et al. 2010).

Ruta genus from Rutaceae includes 14 species in the world and 2 species ( $R$. graveolens and $R$. chalepensis) in Iran and India. $R$. chalepensis can be found as wild plant in southern region of Iran (Mozaffarian 1996). R. graveolens has been used for reducing the oxidative severity of zinc deficiency in experimental diabetes through its hypoglycemic and antioxidant actions (Hamdiken et al. 
2017). R. graveolens L. (Yuin Siang, Sodab, bitter herb or Rue) is a medicinal plant used since time immemorial in ethnobotany (Nazish et al. 2009). It is cultivated as a medicinal and ornamental herb in many countries including Iran and India (Kannan and Babu 2012). The species has been used in America, Asia, and Europe for the treatment of many diseases having various pharmacological activities (Diwan et al. 2012, Gentile et al. 2015, Amabye and Shalkh 2015, Malik et al. 2017). More than 100-120 compounds have been identified up to now from $R$. graveolens root and aerial part. These compounds belong to some major classes of substances: acridone alkaloids, coumarins, flavonoids, essential oil and fluoroquinolones. These phytochemical compounds may find potential applications in pharmaceutical and drug industry (EMEA 1999, Kannan and Baba 2012, Asgarpanah and Khoshkam 2012). $R$. graveolens essential oils detection was done by Dzhurmanski (2011). R. montana aerial part extract exhibits a potent hypoglycemic effect in normal rats and an antidiabetic effect in STZ-induced rats (Farid et al. 2017). Mahmoud et al. (2015) showed marked protective effect of $R$. graveolens extract against AC-induced hyperammonemia in rats through its antioxidant and antiinflammatory efficacies. Toserkani et al. (2012) examined lipid profiles, glucose, and hemogram changes after administration of $R$. graveolens extract in diabetic rats. The rats showed a significant decrease in cholesterol and LDL-c levels, whereas no significant changes were seen in glucose, triglycerides, VLDL-c, and HDL-c values indicating that $R$. graveolens extract has significant effects on total cholesterol and LDL-c in diabetic rats (Toserkani et al. 2012). Also powerful hypolipidemic properties of $R$. graveolens flavonoids were reported by Koshy and Vijayalakshmi (2001). Decreasing lipid peroxidation product and increasing antioxidant enzymes activities by $R$. graveolens have been reported (Ratheesh et al. 2009). Also protective effects of isolated polyphenolic and alkaloid fractions of Ruta graveolens on acute and chronic models of inflammation was studied (Ratheesh et al. 2010).

Rutin, Quercetin, Kaempferol and Vitexin were found in $R$. graveolens aerial part (Figueroa-Valverde et al. 2009; Noori et al. 2015). Rutin is a flavonoid found in many plants having highly potent and shows a wide range of biological activities including anti-inflammatory, antioxidant, neuroprotective, nephroprotective, hepatoprotective and antidiabetic effects (Ghorbani 2017) with increasing insulin receptor kinase activity on kidney (Hsu et al. 2014). Ahmad et al. (2010) studies showed antihyperglycemic and antihyperlipidemic efficacy of $R$. graveolens extract and Rutin in Nicotinamide Streptozotocin-induced diabetic rats which may be mediated via pancreatic and extrapancreatic effects (Ahmad et al. 2010). Antidiabetic and cytotoxicity of the species as a traditional treatment for diabetic cases were studied (Van Huyssteen et al. 2011). In this research isolation, purification and identification of $R$. graveolens aerial part flavonoid compounds were done. Flavonoids compounds and total extracts of the species effects on rat glucose, fat and urine in comparison with antihyperglycemia, antihyperlipidemia and antihyperuricemia synthetic drugs were simultaneously investigated.

\section{MATERIALS AND METHODS}

\section{Extraction and identification of flavonoids from $R$ uta graveolens $\mathrm{L}$. aerial part}

Ruta graveolans L. (Rue) aerial part samples were collected from around Yazd villages, Iran. The plant species were identified and authenticated using valuable and available references (Ghahreman 1994, Rechinger 1966). The plant material was dried in the shade and prepared by grounding into fine powder $(100 \mathrm{~g})$. Extraction was done using perculation method with $70 \%$ ethanol in three steps for $72 \mathrm{~h}$ and all three extracts mixed together. This initial ethanolic extract was dried at $40^{\circ} \mathrm{C}$ and 40 $\mathrm{m} / \mathrm{sec}$ using Heidolph Rotary evaporator Laborota 4000/G1 (Noori 2002). The effective amount of active ingredient per kilogram of dry matter was calculated by weight/volume after dissolving the dry extract in $70 \%$ ethanol; henceforth referred to as crude extract. A portion of the crude extract is kept as is, while the rest of the extract was used to prepare the flavonoid extract.

\section{Flavonoids extract preparation using acid hydrolysis method}

To $200 \mathrm{~mL}$ of a total alcoholic extract was added 200 $\mathrm{mL}$ of Chloride acid $2 \mathrm{M}$ hydrochloric acid and placed in water bath at $100^{\circ} \mathrm{C}$ for 30 minutes. After cooling, $200 \mathrm{~mL}$ ethyl acetate was added to separate and the flavonoid extract from the non-flavonoids extract. The flavonoid extract, soluble in ethyl acetate at $40^{\circ} \mathrm{C}$ and $40 \mathrm{~m} / \mathrm{sec}$, was distilled off in a vacuum. Flavonoids content (gram per kilogram of dry plant matter) was measured by weight/volume method after dissolving the dry extract in $70 \%$ ethanol. Then flavonoids in aqueous-ethanolic extract were isolated, detected and identified by two-dimensional paper and thin layer chromatography according to the methods described by Markham (1982). The flavonoids extracted from the plant aerial part were kept in dark vials and stored in cool conditions until further use.

\section{Flavonoid identification by 2-dimensional paper and thin layer chromatography}

After preparation spotted Whatman No 1 chromatogram with concentrated flavonoids extract and Rutin (=Quercetin 3-O-rutinoside) as a standard, the paper was developed in BAW (n-BuOH-HOAc- $\mathrm{H}_{2} \mathrm{O}=4: 1: 5 ; \mathrm{V} / \mathrm{V}$; upper layer), $1^{\text {st }}$ direction, and HOAc ( $=15 \%$ aqueous acetic acid $), 2^{\text {nd }}$ direction. Then paper was studied in UV $366 \mathrm{~nm}$ and any dark absorbing and fluorescent spots were marked. $\mathrm{R}_{f}$ values in BAW and $15 \%$ HOAc were calculated. Hydrolyzed flavonoids extract was applied as spot on thin layer chromatogram (cellulose). Co-chromatography with standards was also performed where possible. Flavonoid standards available for comparison during the study were apigenin, chrysin, genistein, hesperidin, isorhamnetin, kaempferol, luteolin, morin, myricetin, naringenin, 
quercetin, rhamnetin, rutin, tricine and vitexin (all obtained commercially, Rutin from Merck, apigenin and luteolin from sigma and the rest from Fluka). TLC plate was viewed in UV245 $\mathrm{nm}$ each spot $\mathrm{R}_{f}$-values and color comparing to standards helped flavonoids identification after running in solvents (Mabry et al. 1970; Markham 1982).

\section{Experimental animals}

Sixty adult male Wistar rats weighing $200 \pm 50 \mathrm{~g}$ were selected from the Arak University animal house. They were kept in plastic cages at $22 \pm 2^{\circ} \mathrm{C}$ with $12 \mathrm{~h}$ light, $12 \mathrm{~h}$ dark cycle and free access to diet during experiments and without any noise and contamination. The animals were randomly divided into twelve groups based on Table 1 $(n=5)$. To induce diabetes Streptozotocin (STZ) was injected intraperitoneally (50 $\mathrm{mg} \mathrm{kg}^{-1} \mathrm{~b}$. wt.) and rat with a blood sugar $\geq 200 \mathrm{mgdl}^{-1}$ was considered as diabetic rat. The rat blood sugar level was measured using glucometer at the beginning of the experiment to confirm the normal blood sugar and after 7 days to check the rise in blood sugar in diabetic rats. After the establishment of diabetes, all animals have treated treatments orally for two weeks based on Table 1. Allopurinol as antihyperuricemia, Atorvastatin as antihyperlipidemia and Metformin as antihyperglycemia synthetic drugs were used. The weight of experimental animals was measured before treatment (W1 and the weight after treatment (W2) using laboratory rat balance.

After two weeks of treatment, rats were anesthetized by chloroform, blood samples were taken by heart puncture, and heparinized plasmas were separated for determination of lipid profiles, glucose and blood urea.

\section{Biochemical estimations}

The plasma levels of blood cholesterol, glucose, triglycerides and urea were determined spectrophotometrically using enzymatic colorimetric assay kits (Cholesterol CHOD-PAP 95008, Glucose GOD-PAP 95012, Triglycerides GPO-PAP 95007 and Urea UV-TESE 95008) in Sina Medical Laboratory, Iran.

Table 1. Experimental groups, showing their codes and treatments

\begin{tabular}{lll}
\hline Code & Groups & Treatments \\
\hline C & Control & $0.5 \mathrm{ml} \mathrm{distilled} \mathrm{water}$ \\
CS & Control Streptozotocin & $0.5 \mathrm{ml} \mathrm{distilled} \mathrm{water}$ \\
CAt & Control Atorvastatin & $0.03 \mathrm{mg} / \mathrm{kg}$ Atorvastatin \\
SAt & STZ + Atorvastatin & $0.03 \mathrm{mg} / \mathrm{kg}$ Atorvastatin \\
CMe & Control Metformin & $1.25 \mathrm{mg} / \mathrm{kg}$ Metformin, \\
SMe & STZ + Metformin & $1.25 \mathrm{mg} / \mathrm{kg}$ Metformin \\
CAl & Control Allopurinol & $0.75 \mathrm{mg} / \mathrm{kg}$ \\
SAl & STZ + Allopurinol & $0.75 \mathrm{mg} / \mathrm{kg}$ \\
CRF & Control Ruta flavonoids & $0.25 \mathrm{mg} / \mathrm{per} \mathrm{kg} \mathrm{flavonoids}$ \\
& extract & extract \\
SRF & STZ + Ruta flavonoids & $0.25 \mathrm{mg} / \mathrm{kg}$ \\
& extract & \\
CRT & Control Ruta total extract & $0.33 \mathrm{mg} / \mathrm{per} \mathrm{kg} \mathrm{total} \mathrm{extract}$ \\
SRT & STZ + Ruta total extract & $0.33 \mathrm{mg} / \mathrm{kg}$ \\
\hline & &
\end{tabular}

\section{Statistical analysis}

All of data were expressed as the mean \pm SE and then analyzed using SPSS 16.0 software. These analyses were performed using Fisher's, Chi-square, simple linear regression, Spearman correlation coefficient and ANOVA $(P<0.05, P<0.01)$

\section{RESULTS AND DISCUSSION}

\section{Phytochemical results}

Results showed aerial part of $R$. graveolens contains flavones $C$ and $C$ - $/ O$ glycosides, flavonoid sulfates and had no aglycones (Figure 1). Flavonoids including apigenin, chrysin, isorhamnetin, kaempferol, myricetin, quercetin, rutin, and vitexin were found in the species aerial part (Figure 2). Quantification of R. graveolens showed 329/99 $\mathrm{g}$ active ingredient/ $\mathrm{kg}$ plant dry weight (g/kg DW) effective material and $257.7 \mathrm{~g} / \mathrm{kg} \mathrm{DW}$ of flavonoids.

\section{Weight, blood serum glucose, cholesterol, triglycerides, and urea determination}

Table 2 shows mean \pm SE of weight, blood serum glucose, cholesterol, triglycerides and urea determination in treated rats in comparison with control. Also, Figure 3 shows comparison of weight changes and studied blood serum parameters in control and treated rats.

\section{Data statistical analysis results}

Table 3 shows simple linear regression with treatment type variant and studied parameters. Statistical analysis data results with 1-tailed (Spearman) method using SPSS for determination of correlation between blood serum glucose, cholesterol, triglycerides, urea and weight in experimental rats was done $(P \leq 0.05, P \leq 0.01)$. Also, Data analysis using ANOVA method with treatments consideration as dependant variant has been done $(P \leq 0.05$ that confirmed each other. So, Data analysis results using ANOVA method has been shown in Table 4.

\section{Discussion}

Ruta species are important because many active compounds and hitherto many different secondary metabolites such as flavonoids have been isolated and identified from them. Kannan and Baba (2012) recorded more than 120 different phytochemical compounds from $R$. graveolens root and aerial parts. Our study showed six flavone $C$ and $C$ - $/ O$ glycosides and flavonoid sulfates presence in the species aerial part. Also, apigenin, chrysin, isorhamnetin, kaempferol, myricetin, quercetin, rutin, and vitexin were identified using chromatographical methods. These results are similar to Figueroa-Valverde et al. 2009, Noori et al. (2015). Isolation and identification of rutin and quercetin from $R$. graveolens have been reported by some researchers (Ravindran and Divakaran 2012; Eldalawy 2017). As our results show, $R$. graveolens having 329/99 $\mathrm{g} / \mathrm{kgDW}$ of effective material and $2577 \mathrm{gr} / \mathrm{kg} \mathrm{DW}$ of flavonoids, is a medicinal plant and good natural source of pharmaceutical properties. 

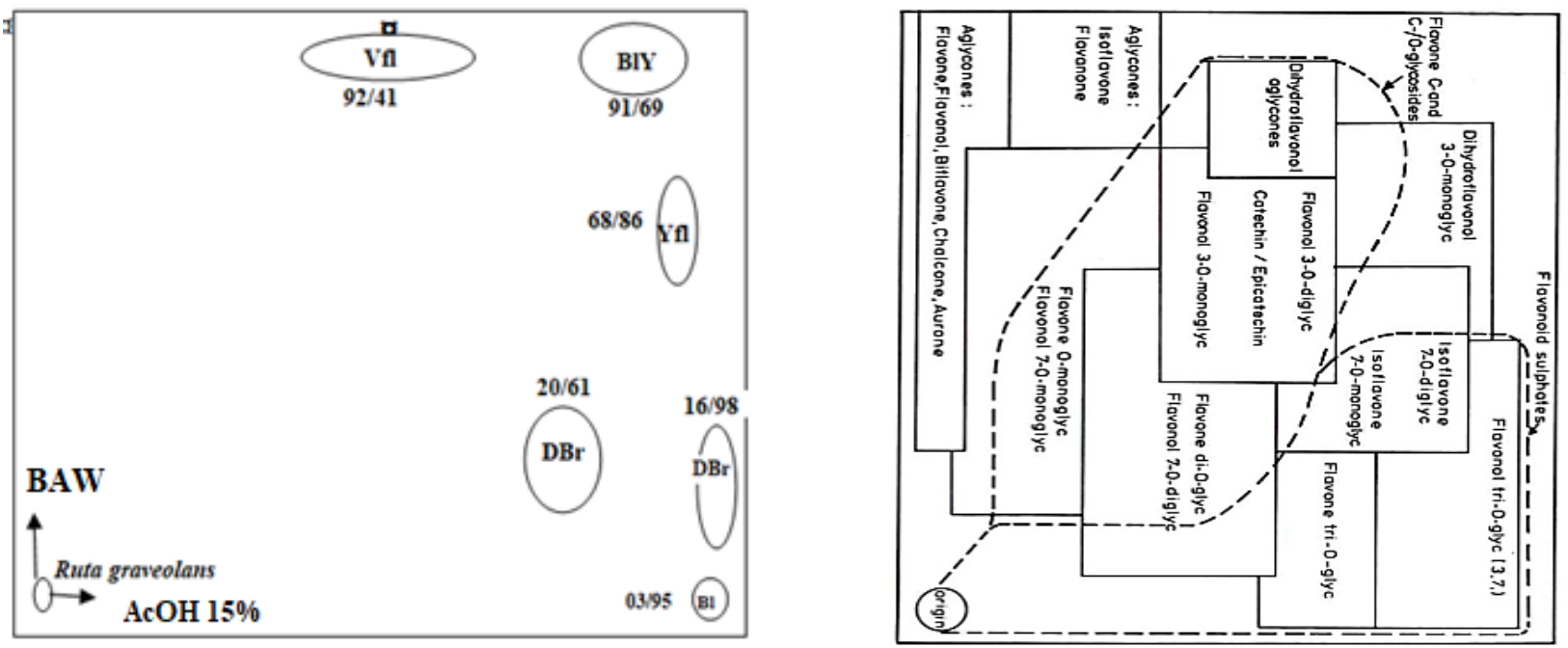

Figure 1. Two dimensional paper chromatography results of Ruta graveolens aerial part. Left numbers are spot $R f$ in BAW and right numbers are Spot $R f$ in AcOH $15 \%$. Note: Bl=blue, Br+brown, D=dark, fl=fluorescence, $\mathrm{V}=$ violet, $\mathrm{Y}=$ yellow (Based on Mabry et al. 1970; Markham 1988)

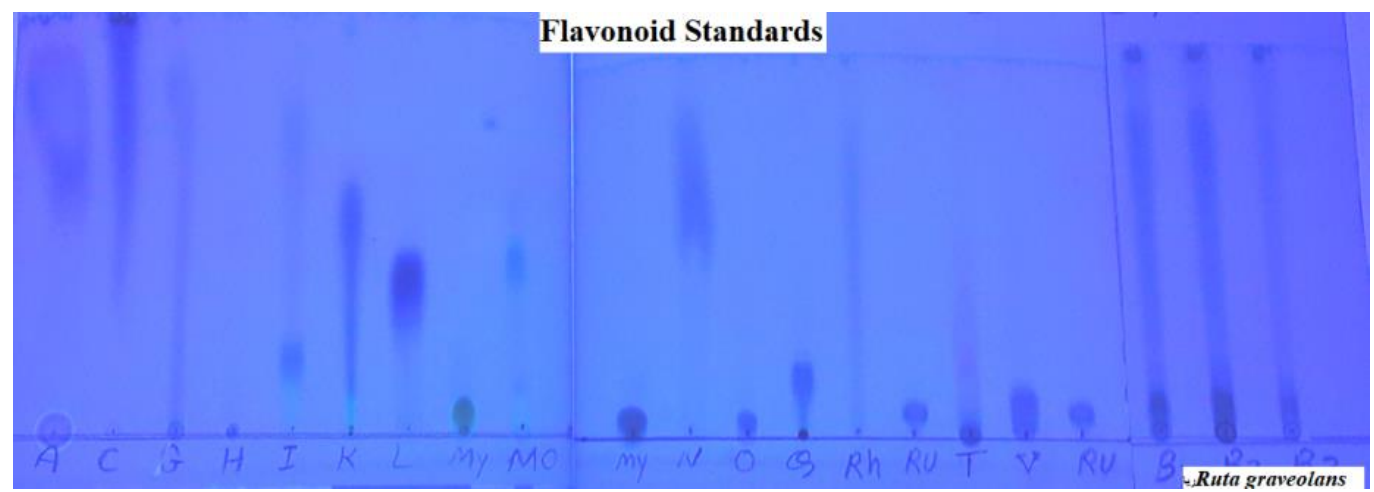

Figure 2. Ruta graveolens TLC chromatogram of used flavonoid standards in CAW; Abbreviations: $\mathrm{A}=\mathrm{Apigenin}, \mathrm{C}=\mathrm{Chrysin}, \mathrm{G}=$ Genistein, $\mathrm{H}=$ Hesperidin, $\mathrm{I}=$ Isorhamnetin, $\mathrm{K}=$ Kaempferol, $\mathrm{L}=$ Luteolin, Mo = Morin, My = Myricetin, $\mathrm{N}=\mathrm{Naringenin}, \mathrm{Q}=$ Quercetin, $\mathrm{Rh}=$ Rhamnetin, $\mathrm{Ru}=$ Rutin, $\mathrm{T}=$ Tricine and $\mathrm{V}=$ Vitexin (all obtained commercially from Merck, apigenin, luteolin and hesperidin from Sigma and the rest from Fluka)

Table 2. Weight and studied blood serum parameters determination in treated rats in comparison with control; for code explanations refer to Table 1.

\begin{tabular}{|c|c|c|c|c|c|c|c|c|}
\hline \multirow[b]{2}{*}{ Groups } & \multicolumn{8}{|c|}{$\mathrm{M} \pm \mathrm{SE}$} \\
\hline & $\xi$ & $\stackrel{N}{3}$ & $\sum_{j}^{3}$ & $\begin{array}{c}3 \\
\text { à } \\
3\end{array}$ & 光 & অ류 & 홀 & ๒ \\
\hline $\mathrm{C}$ & 194.2(3.3) & $237.4(4.9)$ & 1.2 & 43.2 & $214(4.3)$ & $61.3(3.6)$ & $56.3(1.9)$ & $118(12.7)$ \\
\hline $\mathrm{CS}$ & $239.7(14)$ & $230.2(7.8)$ & 1.0 & -9.5 & $568(10.8)$ & $70.8(2.4)$ & $75(4.2)$ & $151(21.2)$ \\
\hline CAt & $225(10.2)$ & $254.3(12.3)$ & 1.1 & 29.3 & $235.7(27.3)$ & $52(8.0)$ & 63(5.9) & $62.3(0.5)$ \\
\hline SAt & $225(10.2)$ & $247.8(4.8)$ & 1.1 & 22.8 & $576.3(4.7)$ & $71(20.1)$ & $58.7(3.3)$ & 67.7(8.0) \\
\hline $\mathrm{CMe}$ & 247.3(4.5) & $276.2(36.9)$ & 1.1 & 28.9 & 193.7(46.2) & $50(3.5)$ & 61.7(6.6) & $120.3(5.9)$ \\
\hline $\mathrm{SMe}$ & 301.3(8.2) & $276.2(36.9)$ & 0.9 & -25.3 & $580.7(22.2)$ & $62.2(5.5)$ & $62(5.7)$ & $116.3(10.8)$ \\
\hline $\mathrm{CAl}$ & 266.7(11.8) & 298.2(9.7) & 1.1 & 31.5 & $567.3(47.6)$ & $80.9(11.2)$ & $60(2.8)$ & $59.3(7.5)$ \\
\hline SAl & 248.3(1.9) & $210.9(14.5)$ & 0.8 & -37.4 & $573.7(6.9)$ & $77.2(7.8)$ & $61.3(6.2)$ & $50.7(10.5)$ \\
\hline CRF & $201(9.2)$ & $245.5(10.5)$ & 1.2 & 44.5 & $243(36.8)$ & $40.8(1.3)$ & $50(2.8)$ & $48.3(1.9)$ \\
\hline SRF & $259(7.8)$ & $244(18.3)$ & 0.9 & -15 & $569(34.7)$ & $112.2(4.3)$ & $46.3(3.3)$ & $42.3(1.9)$ \\
\hline CRT & $205.5(4.3)$ & $316.5(43.0)$ & 1.5 & 111 & $611.3(21.2)$ & $113(10.5)$ & $58.7(6.6)$ & $117(2.8)$ \\
\hline SRT & $231.5(19.4)$ & $221.2(33.2)$ & 0.9 & -10.3 & $221(19.6)$ & $55.1(4.4)$ & $53.7(2.9)$ & $220.7(12.3)$ \\
\hline
\end{tabular}

Note: $\mathrm{W} 1=$ the weight before treatment, $\mathrm{W} 2=$ the weight after treatment, $\mathrm{Gl}=$ glucose, $\mathrm{Ur}=\mathrm{Urea}, \mathrm{Ch}=\mathrm{Cholesterol}, \mathrm{Tg}=$ Triglycerides, $\mathrm{C}=$ Control, $\mathrm{CS}=\mathrm{STZ}$ control, At = Atorvastatin, $\mathrm{Me}=$ Metformin, $\mathrm{Al}=$ Allopurinol, $\mathrm{S}=$ streptozotocin, $\mathrm{R}=$ Ruta graveolans, $\mathrm{F}=$ Flavonoids, $\mathrm{T}=$ total, $\mathrm{M}=$ mean, $\mathrm{SD}=$ standard 


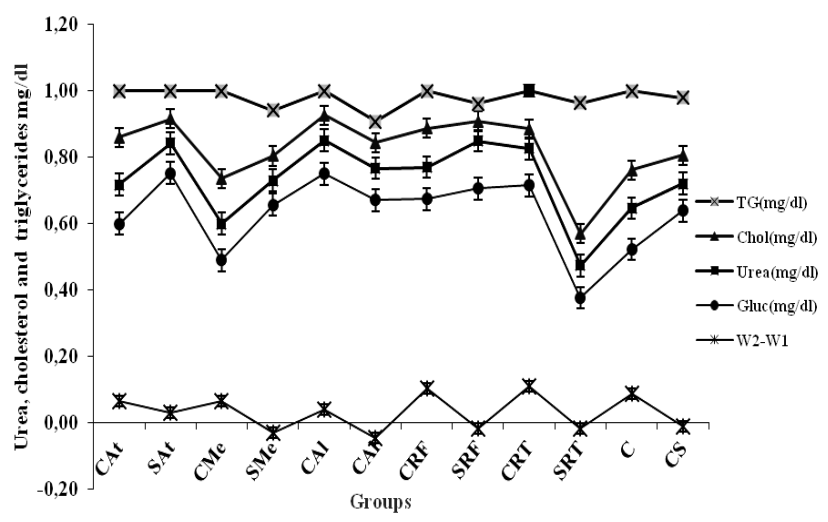

Figure 3. Comparison of mean weight variety and studied blood serum parameters in control and treated rats. Refer to Tables 1 and 2 for abbreviations explanation

Table 3. Simple linear regression with treatment type variant and studied parameters

\begin{tabular}{|c|c|c|c|c|}
\hline \multicolumn{5}{|c|}{ Model Summary b } \\
\hline Model & $\mathbf{R}$ & $\begin{array}{c}\mathbf{R} \\
\text { Square }\end{array}$ & $\begin{array}{l}\text { Adjusted R } \\
\text { Square }\end{array}$ & SE the Estimate \\
\hline 1 & $.924 a$ & .853 & .773 & 4.00484E-1 \\
\hline
\end{tabular}

Note: a. Predictors: (Constant), Blood triglycerides, Second weight, Blood urea, W2/W1, Blood cholesterol, Blood glucose. b. Dependent Variable: Treatment

Table 4. Data analysis results of Ruta graveolens total, flavonoids and non-flavonoids extracts on weight, blood glucose, cholesterol, triglycerides and urea in experimental rats comparing used synthetic drugs using ANOVA method $(P \leq 0.05)$

Coefficients $^{\mathrm{a}}$

\begin{tabular}{|c|c|c|c|c|c|}
\hline \multirow{2}{*}{ Model } & \multicolumn{2}{|c|}{$\begin{array}{c}\text { Unstandardized } \\
\text { coefficients }\end{array}$} & \multirow{2}{*}{$\begin{array}{c}\begin{array}{c}\text { Standardized } \\
\text { coefficients }\end{array} \\
\text { Beta } \\
\end{array}$} & & \multirow{2}{*}{ Sig. } \\
\hline & B & SE & & & \\
\hline (Constant) & 1.984 & .819 & - & 2.423 & $* .034$ \\
\hline Second wiegth & -.010 & .005 & -.537 & -2.090 & .061 \\
\hline $\mathrm{W} 2 / \mathrm{W} 1$ & 3.124 & .651 & .943 & 4.798 & $* .001$ \\
\hline Blood glucose & .001 & .001 & .162 & .738 & .476 \\
\hline Blood urea & .006 & .006 & .227 & 1.013 & .333 \\
\hline Blood cholesterol & -.047 & .022 & -.442 & -2.164 & .053 \\
\hline Blood triglycerids & .009 & .002 & .665 & 4.701 & $* .001$ \\
\hline
\end{tabular}

Table 2 shows the lowest blood glucose levels in treated Metformin control (CMe $193.7 \mathrm{mg} / \mathrm{dL}$ ) and control (C 214 $\mathrm{mg} / \mathrm{dL}$ ) rats respectively (Table 2 , Figure 3 ). The highest blood glucose levels were observed in control treated Rue total extract (CRT $611.3 \mathrm{mg} / \mathrm{dL}$ ) and diabetic treated Metformin rats (SMe $580.7 \mathrm{mg} / \mathrm{dL}$ ), respectively (Table 2, Figure 3). Diabetic rats treated with $R$. graveolens total extract (SRT $221 \mathrm{mg} / \mathrm{dL}$ ) had the lowest blood glucose levels nearly similar control (C $214 \mathrm{mg} / \mathrm{dL}$ ) and CMe groups. These results show that Rue can be considered as antidiabetic plant because it has reduced blood glucose level in diabetic rats. Interestingly, rue treatment increase blood glucose level in control (Table 2, Figure3). It is seemed that using rue extract in health people is not only useful but also caused some disorder in the body by the reason toxicity and damaging the kidney or other entrails. Farid et al. (2017) showed useful effects of Rue aerial part for diabetic rat therapy. Also Eddouks et al. (2016) reported decreasing blood glucose level STZ-induced diabetic rats using Rue aerial part aquatic extract. Antidiabetic effects of $R$. graveolens with three other plants have been reported for diabetic patient therapy in traditional prescription (Van Huyssteen et al. 2011). Ahmed et al. (2010) did not show qualified anti-diabetic effect for Rue but their results revealed that both $R$. graveolens and Rutin exhibit antihyperglycemic and antihyperlipidemic properties via their insulinogenic effects, decreasing intestinal glucose and cholesterol absorption, improving peripheral insulin action, affecting mediators of insulin resistance, enhancing peripheral glucose uptake and decreasing hepatic glucose output in addition to the ameliorating effect on the antioxidant status in this condition. Their results suggest that both Rue and Rutin improve glucose tolerance and this amelioration seemed to be mediated via alleviation of the islet architecture, enhancement of insulin release, insulin binding affinity, and peripheral glucose uptake and decreasing intestinal glucose absorption in addition to decreasing the activity of gluconeogenic and glycogenolytic enzymes (Ahmed et al. 2010).

The lowest blood urea level was observed in CRF group with $40.8 \mathrm{mg} / \mathrm{dL}$, then CMe $(50 \mathrm{mg} / \mathrm{dL})$, CAt $(52 \mathrm{mg} / \mathrm{dL})$ and SRT $(55.1 \mathrm{mg} / \mathrm{dL})$ were respectively. CRT group (113 $\mathrm{mg} / \mathrm{dL}$ ) had the highest blood urea level (Table 2). These results show that Rue flavonoids extract, Metformin and Atorvastatin caused decreasing blood urea in control and health rats, but Rue total extract has decreased blood urea in STZ-induced diabetic rats. Both $\mathrm{C}$ and CRF groups showed lower blood urea than two Allopurinol treated groups (CAl and SAl). Mahmoud (2012), Mahmoud et al. (2014 and 2015) and also Ganeshpurkar and Saluja (2017) studies showed $R$. graveolens effects on blood serum urea, , and uric acid reduction. Blood urea nitrogen (BUN) test is done to see how well kidneys are working. If kidneys are not able to remove urea from the blood normally, BUN level rises. They believed that these properties and protective effects of the plant are by the reason rutin presence in the Rue. Our results confirmed Rutin in Rue flavonoids extract.

Both CRF and SRF groups showed the lowest cholesterol (46.3 and $50 \mathrm{mg} / \mathrm{dL}$ ) respectively, and CS group had the highest level. These results show Rue flavonoids extract on cholesterol reduction in health and diabetic individuals. Toserkani et al. (2012) reported cholesterol and LDL reduction using the plant extract, although were not observed any qualified changes in glucose, triglycerides, VLDL and HDL levels. They showed cholesterol and LDL reduction levels in diabetic rats after Rue extracts medication. Our results showed that using both Rue total and flavonoids extracts caused cholesterol reduction in diabetic rats (SRF and SRT) in 
comparison with control (C) and treated Atorvastatin diabetic rats (SAt) (Table 2). The cluster of lipid abnormalities associated with type 2 diabetes is defined by a high concentration of TG and small dense LDL and a low concentration of HDL cholesterol. Diabetes carries a high risk of atherosclerosis, and cardiovascular disease, especially coronary heart disease (CHD) and stroke, is by far the leading cause of death among patients with type 2 diabetes (Bitzur et al. 2009).

The lowest mean blood serum triglycerides were observed in SRF (42.3 mg/dL) and CRF (48.3 mg/dL) groups respectively. SRT group showed the highest level of triglycerides $(220.7 \mathrm{mg} / \mathrm{dL})$ comparing to $\mathrm{C}$ and CAt groups. These results confirmed that $R$. graveolens flavonoids extract has antitriglycerides effect in comparison with its total extract (Table 2). As Figure 1 shows SRT and CMe groups had respectively the most glucose, urea and cholesterol reductions levels. But total and flavonoids extracts and Metformin were not effective on triglycerides reduction. These results are similar Toserkani et al. (2012) studies. Malika et al. (2012) reported antilipidemic effects of Rue.

Histotechniques studies of experimental rat kidneys showed the highest renal damage in control diabetic rats (Noori et al. 2018). The least renal damage was observed in the STZ-diabetic rats treated with the plant total extract (SRT) comparing SMe group that we will separately report. These results show that using Rue as antidiabetic medicinal plant has protective effect comparing Metformin by the reason of having phenolic and alkaloids compounds (EMEA 1999; Kannan and Baba 2012; Asgarpanah and Khoshkam 2012).

As Table 4 shows, weight, blood triglycerides, and glucose levels were significant in treated rats. These results show that Rue and its chemical compounds are effective on weight, blood cholesterol and glucose (Starry numbers show significant correlation between the studied parameters). As Wang et al. (2009) showed that serum chemerin is correlated with insulin level, body fat disposition, and lipid metabolism which suggesting that it may play a role in the pathophysiology of obesity and metabolic syndrome. In Table 2 cholesterol reduction was observed in diabetic rats treated with Rue total and flavonoids extracts. Also, Toserkani et al. (2012) reported cholesterol and LDL reduction in treated Rue extract diabetic rats. Farid et al. (2017) studies also showed a beneficial effect on using Rue aerial parts for STZ-diabetic rats' treatment and blood glucose reduction in non-diabetic rats.

Observation of the least renal damage in the STZdiabetic rats treated with the Rue total extract and the highest renal damage in control diabetic rats (Noori et al. 2018) indicate that $R$. graveolens extract and its Rutin contained anti-hyperglycemia and protective properties. Ratheesh et al. (2010) recorded protective effects of isolated polyphenolic and alkaloid fractions of $R$. graveolens on acute and chronic models of inflammation. Long et al. (2005) studied on Drynaria fortune flavonoids protection against acute renal failure. They found that flavonoid fraction prevents nephrotoxicity, improves kidney function and promotes kidney primary epithelial tubular cell regeneration (Long et al. 2005). Rutin as a water-soluble flavonoid glycoside has the most potent uterotonic (Salib et al. 2014, Ganeshpurkar and Saluja 2017), anti-diabetic (Hosseinzadeh and Nassiri-Asl 2014), anti-hyperglycemic, antioxidant effects (Kamalakkannan and Prince 2006) with increasing insulin receptor kinase activity on kidney (Hsu et al. 2014).

In conclusion, $R$. graveolens having effective phytochemical compounds especially flavonoids can be used as anti-hyperglycemia natural drug. Its flavonoids as antioxidant protect kidney against renal failure. Studying Rue chemical compounds effects on diabetic patients alone or with synthetic drugs can be useful. Then prescription Rue aerial part in human diet is suggested.

\section{ACKNOWLEDGMENTS}

This research was supported by Research Deputy of Arak University. The authors' special thanks go to Deputy Planning and Support of Faculty of Science. We would like to thank of Department of Biology in Arak University.

\section{REFERENCES}

Adeneye AA. 2008. Hypoglycemic and hypolipidemic effects of methanol seed extract of Citrus paradise Macfad (Rutaceae) in alloxan-induced diabetic Wistar rats. Nig Q J Hosp Med. 18 (4): 211-215.

Ahmed OM, Moneim AA, Yazid IA, Mahmoud AM. 2010. Antihyperglycemic, antihyperlipidemic and antioxidant effects and the probable mechanisms of action of Ruta graveolens infusion and rutin in nicotinamde streptozotocin-induced diabetic rats. Diabetol Croat 39: 15-35.

Alarcon-Aguilara FJ, Roman-Ramos R, Perez-Gutierrez S, AguilarContreras A, Contreras-Weber CC, Flores-Saenz JL. 1998. Study of the anti-hyperglycemic effect of plants used as antidiabetics. J Ethnopharmacol 61 (2): 101-110.

Amabye T, Shalkh TM. 2015. Phytochemical Screening and Evaluation of Antibacterial Activity of Ruta graveolens L.-A Medicinal Plant Grown around Mekelle. Nat Prod Chem Res. 3:6. DOI: 10.4172/2329-6836.1000195.

Arif T, Sharma B, Gahlaut A, Kumar V, Dabur R. 2014. Antidiabetic agents from medicinal plants: A review. Chem Biol Lett 1 (1): 1-13.

Arumugam G, Manjula P, Paari N. 2013. A review: Antidiabetic medicinal plants used for diabetes mellitus. J Acute Dis. DOI: 10.1016/S2221-6189(13)60126-2.

Asgarpanah J, Khoshkam R. 2012. Phytochemistry and pharmacological properties of Ruta graveolens L. J Med Plants Res 6 (23): 39423949.

Bitzur R, Cohen H, Kamari Y, Shaish A, Harats D. 2009. Triglycerides and HDL Cholesterol Stars or second lead in diabetes? Diabetes Care 32 (Suppl 2): S373-S377.

Dineshkumar B, Mitra A, Mahadevappa M. 2010. Antidiabetic and hypolipidemic effects of mahanimbine (carbazole alkaloid) from Murraya koenigii (Rutaceae) leaves. Intl J Phytomed 2 (1): 22-30.

Diwan R, Shinde A, Malpathak N. 2012. Phytochemical composition and antioxidant potential of Ruta graveolens L. in vitro culture lines. J Bot 2012, Art 685427, 6. DOI:10.1155/2012/685427.

Dzhurmanski A; Zhekova G, Angelova D. 2011. Accumulation dynamic of Ruta graveolens L. essential oil. Agric Sci Technol 3 (4): 343-345.

Eddouks M, Farid O, Hebi M, Ajebli M, Benaji B, El Bouhali B. 2016. Antidiabetic effect of Rutamontana L. in streptozotocin-induced diabetic rats. J Diabetes Metab. 7: 8 (Suppl). 12th European Diabetes Congress September 15-17, 2016 Berlin, Germany. DOI: 10.4172/2155-6156.C1.052. 
El Agraa SE, El Badwi SM, Adam SE. 2002. Preliminary observations on experimental Ruta graveolens toxicosis in Nubian goats. Trop Anim Health Prod. 34 (4): 271-81.

Eldalawy R. 2017. Quantitative estimation of rutin in rue (Ruta graveolens $\mathrm{L}$.) cultivated in Iraq with the evaluation of its antioxidant activity. Asian J Pharm Clin Res. 10. 353-355.

EMEA. 1999. Committee for veterinary medicinal products (Ruta graveolens), The European Agency for the evaluation of medicinal products.EMEA/MRL/542/98-Final.

Farid O, Hebi M, Ajebli M, Hidani, AE, Eddouks M. 2017. Antidiabetic effect of Ruta montana L. in streptozotocin-induced diabetic rats. J Basic Clin Physiol Pharmacol 1; 28 (3): 275-282.

Figueroa-Valverde L, Díaz-Cedillo F, Camacho-Luis A, Ramos ML. 2009. Induced effects by Ruta graveolens L., Rutaceae, CnidoscoluschayamansaMcVaugh, Euphorbiaceae, and Citrus aurantium L., Rutaceae, on glucose, cholesterol and triacylglycerides levels in a diabetic rat model. Rev Bras Farmacogn 19: 898-907.

Ganeshpurkar A, Saluja AK. 2017. The pharmacological potential of rutin. Saudi Pharm J. 25 (2): 149-164.

Gentile MT, Ciniglia C, Reccia MG, Volpicelli F, Gatti M, Thellung S, Florio T, Melone MA, Amato LC. 2015. Ruta graveolens L. induces death of glioblastoma cells and neural progenitors, but not of neurons, via ERK $1 / 2$ and AKT Activation. PLoS ONE. DOI: 10.1371/journal.pone.0118864.

Ghahreman A.1994, Flore de 1 Iran en couleurnaturelle.InstitutRecherches des Foretset des Paturages. No. 850. Code 061, 002, 002, [Persian].

Ghorbani A. 2017. Mechanisms of anti-diabetic effects of flavonoid rutin, Biomed Pharmacother. 96: 305-312.

Grover K, Yadav S, Vats V. 2002. Medicinal plants of India with antidiabetic potential. J Ethnopharmacol 81 (2002) 81/100. DOI: 10.1016/S0378-8741(02)00059-4.

Hamdiken M, Bouhalit S, Kechrid Z. 2017. Effect of Ruta chalepensis on zinc, lipid profile and antioxidant levels in the blood and tissue of Streptozotocin-induced diabetes in rats fed zinc-deficient diets. Can J Diabet. DOI:10.1016/j.jcjd.2017.08.239.

Hosseinzadeh H, Nassiri-Asl M. 2014. Review of the protective effects of rutin on the metabolic function as an important dietary flavonoid. J Endocrinol Inves. 37 (9): 783-788.

Hsu CY, Shih HY, Chia YC, Lee CH, Ashida H, Lai YK, Weng CF. 2014. Rutin potentiates insulin receptor kinase to enhance insulin-dependent glucose transporter 4 translocation. MolNutr Food Res. 58 (6): 11681176.

Jensen T, Stender S, Deckert T. 1988. Abnormalities in plasma concentrations of lipoprotein and fibrinogen in type 1(insulindependent) diabetic patients with increased urinary albumin excretion.Diabetologia. 31: 142-145.

Kamalakkannan N, Prince PSM. 2006. Antihyperglycaemic and antioxidant effect of Rutin, a polyphenolic flavonoid, in Streptozotocin-Induced diabetic Wistar rats. Basic Clin Pharmacol Toxicol. 98 (1): 97-103.

Kannan R, Babu UV. 2012. Identity and pharmacognosy of Ruta graveolensLinn. Anc. Sci Life. 32 (1): 16-19.

Koshy AS, Vijayalakshmi NR. 2001. Impact of certain flavonoids on lipid profiles potential action of Garcinia cambogia flavonoids. Phytother Res 15: 395-400.

Long M, Qiu D, Li F, Johnson F, Luft B. 2005. Flavonoid of Drynaria fortunei protects against acute renal failure. Phytother Res. 19 (5): 422-427.

Mabry T, Markhm KR. (1970). Thomas MB., "The systematic identification of flavonoids", Speringer-Verlage, Berlin-Heidel berg, New York.

Mahmoud AM, Germoush MO, Soliman AS. 2014. Ruta graveolens mitigates ammonium chloride-induced hyperammonemia by modulating antioxidant status and pro-inflammatory cytokines. Life Sci J 11: 269-275.
Mahmoud AM. 2012. Influence of rutin on biochemical alterations in hyperammonemia in rats. Exp Toxicol Pathol 64: 783-789.

Mahmoud AM, Ahmed RR, Soliman HA, Salah M. 2015. Ruta graveolens and its active constituent rutin protect against diethylnitrosamineinduced nephrotoxicity through modulation of oxidative stress. J App Pharm Sci 5 (10): 16-21.

Malik S, Moraes DFC, do Amaral FMM, Ribeiro MNS. 2017. Ruta graveolens: Phytochemistry, pharmacology and biotechnology. In: Jha S (ed.). Transgenesis and Secondary Metabolism. Springer, Berlin.

Malika H, Samira B, Zine K. 2017. Effect of Rutachalepensison zinc, lipid profile and antioxidant levels in the blood and tissue of Streptozotocin-induced diabetes in rats fed zinc-deficient diets. Can J Diabet 42 (4). DOI: 10.1016/j.jcjd.2017.08.239.

Markham KR. 1982. Techniques of flavonoid identification. Academic Press, London.

Mozaffarian W. 1996. A Dictionary of Iranian Plant Names. Farhang Moaser, Tehran, Iran. [Persian]

Nazish RA, Kaskoos SR, Mir, Amin S, Ali M. 2009. Preliminary pharmacognostical standardisation of Ruta graveolens $\mathrm{L}$. aerial parts. Res J Med Plant 3: 41-44.

Noori M. 2002. Characterization of the Iranian species of Sophora and Ammodendron (Leguminosae; Sophoreae), $\mathrm{PhD}$ Thesis, University of London and Royal Botanic Gardens, Kew, UK.

Noori, M. Jafari, M., Azimi, H., Node-Farahani, M. 2018. Studies of Ruta graveolens total, flavonoids and non flavonoids effective compounds on rat blood glucose, fat and urea in comparison with synthetic drugs, Research Project Report, Deputy of Research \& Technology Department, Arak University, Iran. [Persian].

Noori M, Kobarfard F, Hosseinzadeh Aghdam V, Fakhari S. 2015. Ruta graveolens L. (Rutaceae) aerial part flavonoids, 4th National Cong. on Medicinal Plants-Tehran 2015, Tehran-Iran.

Ratheesh M, Shyni GL, Helen A. 2009. Methanolic extract of Ruta graveolens $\mathrm{L}$. inhibits inflammation and oxidative stress in adjuvantinduced model of arthritis in rats. Inflammopharmacology 17: 100105.

Ratheesh M, Shyni GL, Sindhu G, Helen A. 2010. Protective effects of isolated polyphenolic and alkaloid fractions of Ruta graveolens $\mathrm{L}$. on acute and chronic models of inflammation. Inflammopharmacology 33 (1): $18-24$.

Ravindran PN, Divakaran M. 2012. in Handbook of Herbs and Spices (Second Edition), Volume 2.

Rechinger K. H. 1966. Flora Iranica.No. 36-21 S., 4 Taf

Salib JY, El-Toumy SA, Hassan EM, ShafikNH, Abdel-Latif SM, Brouard I. 2014. New quinoline alkaloid from Ruta graveolens aerial parts and evaluation of the antifertility activity. Nat Prod Lett: Formerly Nat Prod Lett. 28:1335-1345.

Toserkani A, Razi Jalali M, Najafzaheh H. 2012. Changes of lipid profiles, glucose, and hemogram after administration of Ruta graveolens extract in diabetic rats. Comp Clin Pathol 21: 1587-1592.

Van Huyssteen VM, Milne PJ, Campbell EE, van de Venter M. 2011. Antidiabetic and cytotoxicity screening of five medicinal plants used by Traditional African Health Practitioners in the Nelson Mandela Metropole, South Africa. Afr J Tradit Compl Altern Med 8 (2): 150158.

Wang LY, Wei L, Yu HY, Zhang Y, Jia WP. 2009. Relationship of serum Chemerin to obesity and type 2 diabetes mellitus. Zhonghua Yi Xue Za Zhi 89 (4): 235-238.

Weggemans RM, Trautwein EA. 2003. Relation between soy-associated isoflavones and LDL-C and HDL-C cholesterol concentrations in humans: a meta-analysis. Eur J Clin Nutr. 57: 940-946.

Wild S, Roglic G, Green A, Sicree R, King H. 2004. Global prevalence of diabetes: estimates for the year 2000 and projections for 2030 . Diabetes Care 27: 1047-1053. 